\title{
Elevation of MPF and MAPK gene expression, GSH content and mitochondrial distribution quality induced by melatonin promotes porcine oocyte maturation and development in vitro
}

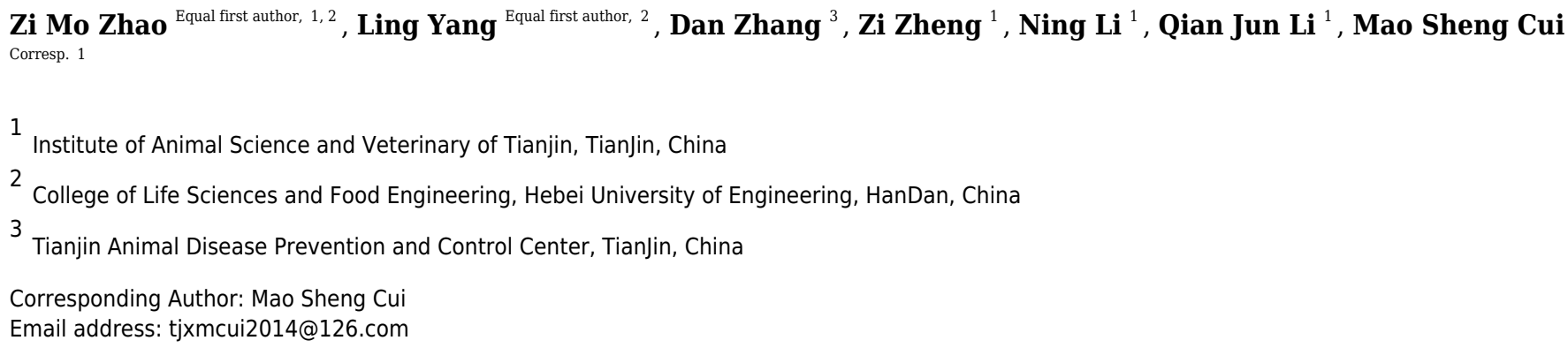

The MPF and MAPK genes play crucial roles during oocyte maturation processes. However, the pattern of MPF and MAPK gene expression induced by melatonin (MT) and its correlation to oocyte maturation quality during the process of porcine oocyte maturation in vitro remains unexplored. To unravel it, in this study, we cultured the porcine oocytes in maturation medium supplemented with $0,10^{-6}, 10^{-9}$, and $10^{-12} \mathrm{~mol} / \mathrm{L}$ melatonin. Later, we analyzed the MPF and MAPK gene expression levels by RT-PCR and determined the maturation index (survival and maturation rate of oocytes). The GSH content in the single oocyte, and cytoplasmic mitochondrial maturation distribution after porcine oocyte maturation in vitro was also evaluated. We also assessed the effects of these changes on parthenogenetic embryonic developmental potential. The oocytes cultured with $10^{-9} \mathrm{~mol} / \mathrm{L}$ melatonin concentration showed higher oocyte maturation rate, and MPF and MAPK genes expression levels along with better mitochondrial distribution than the $0,10^{-6}$, and $10^{-12}$ $\mathrm{mol} / \mathrm{L}$ melatonin concentrations $(p<0.05)$. No significant difference was observed in the survival rates when the oocytes were cultured with different melatonin concentrations. The expression of the MPF gene in the oocytes cultured with $10^{-6} \mathrm{~mol} / \mathrm{L}$ melatonin was higher than with $10^{-12}$ and $0 \mathrm{~mol} / \mathrm{L}$ melatonin, and the expression of the MAPK gene in $10^{-6}$ and $10^{-12}$ group was higher than the control $(p<0.05)$. As far as the embryonic developmental potential is concerned, the cleavage and blastocyst rate of oocytes cultured with $10^{-6}$ and $10^{-9} \mathrm{~mol} / \mathrm{L}$ melatonin was significantly higher than the $10^{-12} \mathrm{~mol} / \mathrm{L}$ melatonin and control. In conclusion, $10^{-9}-10^{-6} \mathrm{~mol} / \mathrm{L}$ melatonin significantly induced the MPF and MAPK gene expression; besides it could also be correlated with GSH content of single oocyte, 
mitochondrial maturation distribution, and the first polar body expulsion. These changes were also found to be associated with parthenogenetic embryo developmental potential in vitro. 
1 Elevation of MPF and MAPK gene expression, GSH

2 content and mitochondrial distribution quality induced by

3 melatonin promotes porcine oocyte maturation and

4 development in vitro

5

6

7

8

9

10

11

ZiMo Zhao ${ }^{1,2 \#, ~ L i n g ~ Y a n g ~}{ }^{2 \#}$, Dan Zhang ${ }^{3}$, Zi Zheng ${ }^{1}$, Ning Li $^{1}$, QianJun $\mathrm{Li}^{1}$, MaoSheng Cui ${ }^{1 *}$

1. Institute of Animal Science and Veterinary of Tianjin, Tianjin 300381, China;

2. College of Life Sciences and Food Engineering, Hebei University of Engineering, Handan 056038, China;

3. Tianjin Animal Disease Prevention and Control Center, Tianjin 300402, China.

Corresponding Author:

MaoSheng Cui

JinJing Road 17 km, XiQing District, TianJin, 300381, China

Email Address:tjxmcui2014@126.com

Authors with “\#” contributed equally to this work.

\section{Abstract}

The MPF and MAPK genes play crucial roles during oocyte maturation processes. However, the pattern of MPF and MAPK gene expression induced by melatonin (MT) and its correlation to oocyte maturation quality during the process of porcine oocyte maturation in vitro remains unexplored. To unravel it, in this study, we cultured the porcine oocytes in maturation medium supplemented with $0,10^{-6}, 10^{-9}$, and $10^{-12} \mathrm{~mol} / \mathrm{L}$ melatonin. Later, we analyzed the MPF and MAPK gene expression levels by RT-PCR and determined the maturation index (survival and maturation rate of oocytes). The GSH content in the single oocyte, and cytoplasmic mitochondrial maturation distribution after porcine oocyte maturation in vitro was also evaluated. We also assessed the effects of these changes on parthenogenetic embryonic developmental potential. The oocytes cultured with $10^{-9} \mathrm{~mol} / \mathrm{L}$ melatonin concentration showed higher oocyte maturation rate, and MPF and MAPK genes expression levels along with better mitochondrial distribution than the $0,10^{-6}$, and $10^{-12} \mathrm{~mol} / \mathrm{L}$ melatonin concentrations $(\mathrm{p}<0.05)$. No significant difference was observed in the survival rates when the oocytes were cultured with different melatonin concentrations. The expression of the MPF gene in the oocytes cultured with $10^{-6} \mathrm{~mol} / \mathrm{L}$ melatonin was higher than with $10^{-12}$ and $0 \mathrm{~mol} / \mathrm{L}$ melatonin, and the expression of the MAPK gene in $10^{-6}$ and $10^{-12}$ group was higher than the control $(\mathrm{p}<0.05)$. As far as the embryonic developmental potential is concerned, the cleavage and blastocyst rate of oocytes cultured with $10^{-6}$ and $10^{-9} \mathrm{~mol} / \mathrm{L}$ melatonin was significantly higher than the $10^{-12} \mathrm{~mol} / \mathrm{L}$ melatonin and control. In conclusion, $10^{-9}-10^{-6} \mathrm{~mol} / \mathrm{L}$ melatonin significantly induced the MPF and MAPK gene expression; besides, it could also be correlated with GSH content of single 
42 oocyte, mitochondrial maturation distribution, and the first polar body expulsion. These changes

43 were also found to be associated with parthenogenetic embryo developmental potential in vitro.

44

45

46

47

48

49

50

51

52

53

54

55

56

57

58

59

60

61

62

63

64

65

66

67

68

69

70

71

72

73

74

75

76

77

78

79

80

81

Keywords: porcine oocyte; melatonin; maturation quality; MPF; MAPK

\section{Introduction}

Oocyte maturation is an extensively used experimental technique in animal reproduction biotechnology. It involves the immature oocyte extraction from the ovaries, and it's in vitro culture until it has reached the maturation stage (Hoelker et al., 2017; Lonergan \& Fair, 2016). During in vitro culture and maturation, oocytes generate a high amount of Reactive Oxygen Species (ROS) as a result of mechanical treatment, air, light, and other factors (Waiz et al., 2016). Although the physiological dose of ROS is favorable for the oocyte maturation and development, excessive ROS leads to adverse effects due to the DNA damage, mitochondrial dysfunction, lipid peroxidation, abnormal protein modification, and so on (Rajani et al., 2012).

Melatonin is an antioxidant, which binds and inhibits the oxygen free radical. Also, it serves as a protective barrier against the oxidative stress damage during oocyte maturation and development primarily by enhancing the intracellular glutathione level (Agarwal \& Majzoub, 2017; Gao et al., 2012; He et al., 2019; Tamura et al., 2008). Glutathione is a crucial factor in the maturation and development of the oocyte as it eliminates the intracellular ROS (Lee et al., 2016). Mitochondria are ATP production sites, which are evenly distributed and diffused across the cytoplasm during the formation of oocytes with a high maturation quality (Cui et al., 2009). Mitochondria lead to energy production during the oocytes maturation and embryo development, and hence the mitochondrial distribution is correlated with oocyte maturation quality (Babayev \& Seli, 2015), as well as with the oocyte fertilization and early embryo development (Chappel, 2013).

In the oocytes meiotic maturation, MAPK performs a vital role in the early embryo development processes, such as the initiation of $\mathrm{GV}$, the promotion of nuclear maturation, and the oocytes maintenance at the MII stage (Tripathi et al., 2010). MPF, a cyclin B1, and cyclin-dependent kinase complex play a crucial in the meiosis maturation of oocytes. It maintains the normal meiosis cycle of oocytes and the normal cleavage of early embryos (Baek et al., 2017; LópezCardona et al., 2017).

Previous studies have comprehensively reported the roles of melatonin in the maturation and embryonic development of bovine oocytes (Liang et al., 2017), sheep oocytes (Xiao et al., 2019), porcine oocytes (Li et al., 2015) and mice oocytes (Nikmard et al., 2016). However, the melatonin-induced MPF and MAPK gene expression and its correlation with the oocyte maturation quality during porcine oocyte maturation in vitro, remains obscure. In-line with our previous findings, we hypothesize that MPF and MAPK genes expression also play a crucial role in the effect of melatonin promoting oocyte maturation quality in vitro. In the current study for the first time, we reported the expression patterns of MPF and MAPK genes induced by $0,10^{-6}$, $10^{-9}$ and $10^{-12} \mathrm{~mol} / \mathrm{L}$ melatonin and its association with oocytes maturation index during porcine oocytes maturation in vitro. The outcome of this study serve as a reference point for the 
82 improvement of oocyte utilization, which in turn will benefit the related biotechnological 83 applications.

84

85

86

87

88

89

90

91

92

93

94

95

96

97

98

99

100

101

102

103

104

105

106

107

108

109

110

111

112

113

114

115

116

117

118

119

120

121

\section{Materials \& Methods}

Unless otherwise stated, all reagents used in the present study were purchased from Sigma Chemicals (St. Louis, MO, USA).

\section{Oocyte collection and in vitro maturation}

Porcine ovaries were procured from a local abattoir. The oocytes were collected from 3-6 mm diameter ovarian follicles by aspirating them with the 18-gauge needle attached to a disposable $20 \mathrm{~mL}$ syringe. We washed the oocytes four times with the Tyrode's lactate (TL)-Hepes-PVA $(0.1 \%)$ and the compact Cumulus and Oocyte Complexes (COCs) were cultured in microdrops of maturation medium supplemented with $0,10^{-6}, 10^{-9}$, and $10^{-12} \mathrm{~mol} / \mathrm{L}$ MT for in vitro maturation (IVM); $100 \mu \mathrm{L}$ microdrop contained $30 \mathrm{COCs}$. All the groups were incubated at $39^{\circ} \mathrm{C}$ with $5 \%$ $\mathrm{CO}_{2}$ in 95\% humidified air for $42 \mathrm{~h}$ (Huang et al., 2016). The maturation medium, TCM199 (with Earle's Salts; Gibco), contained cysteine $(0.1 \mathrm{mg} / \mathrm{mL})$, penicillin $(0.065 \mathrm{mg} / \mathrm{mL})$, porcine follicular fluid (PFF)(10\%), epidermal growth factor $(\mathrm{EGF})(10 \mathrm{ng} / \mathrm{mL})$, equine chorionic gonadotropin (eCG; Intervet Pty. Ltd, Australia) $(10 \mathrm{IU} / \mathrm{mL})$, and human chorionic gonadotrophin (hCG; Intervet Pty. Ltd.)(10 IU/mL).

\section{The assessment of oocyte maturation quality}

After $42 \mathrm{~h}$ of maturation culture, COCs from each group were denuded by gentle pipetting in phosphate-buffered saline (PBS) supplemented with $0.1 \%$ hyaluronidase. The denuded oocytes from different groups were transferred to the TCM199 medium supplemented with $0.5 \%$ fetal bovine serum (FBS) and $25 \mathrm{mM}$ Hepes (for washing). We marked the oocytes as survival oocytes after observing them for homogeneous cytoplasm and intact, bright membrane under a stereomicroscope (Fig.1.A); besides, the matured oocytes were the survival oocytes with the expulsed polar body into the perivitelline space (Fig.1.D). Survival and maturation of the oocytes were validated by the FDA and Hoechst33342 staining, respectively. The survived oocytes were characterized by the presence of bright fluorescence in the ooplasmic membrane (Fig. 1.B); however, the absence of fluorescence indicated dead oocytes (Fig. 1.C). The oocytes with the expulsed polar body exhibited nucleus and polar body fluorescence (Fig. 1.E); however, the oocytes with no expulsed polar body showed fluorescence only in the nucleus (Fig. 1.F). The matured oocytes were used for subsequent experimentations.

\section{Quantification of intracellular glutathione}

As per the method reported by Huang et al., we performed a 5,5'-Dithiobis (2-nitrobenzoic acid) (DTNB)-GSH reductase recycling assay to determine the total intracellular concentration of GSH in a single oocyte of different groups (Zhao et al., 2017). A total of 20-30 oocytes from each group were frozen into a $1.5 \mathrm{~mL}$ centrifuge at $-80^{\circ} \mathrm{C}$ ctill we assayed the GSH content. The frozen oocytes were thawed and homogenized by repeated pipetting during the GSH content detection. Later, we transferred this homogenized solution into a 96-well plate and added a 150 $\mathrm{mL}$ assaying solution to each well. After the solution equilibration at $25^{\circ} \mathrm{C}$ for $5 \mathrm{~min}$, we added 
$12250 \mathrm{~mL}$ of $0.16 \mathrm{mg} / \mathrm{mL}$ nicotinamide adenine dinucleotide phosphate (NADPH) to each well, 123 which led to the formation of 5-thio-2-nitro-benzoic acid. We measured the absorbance at 412

124

125

126

127

128

129

130

131

132

133

134

135

136

137

138

139

140

141

142

143

144

145

146

147

148

149

150

151

152

153

154

155

156

157

158

159

160

161 $\mathrm{nm}$ using a spectrophotometer (Beckman DU-40, USA) for five times at $30 \mathrm{~s}$ interval. The standard curve was plotted for the calculation of GSH value. We divided the value by oocytes number in each sample and detected a blank sample, i.e., without GSH, in our study.

\section{Mitochondrial distribution analysis}

We washed one hundred oocytes from each group for four times in PBS containing 0.2 M sodium phosphate buffer. Oocytes were incubated in TCM-199 medium with $12.5 \mathrm{mmol} / \mathrm{L}$ Mito Tracker Red (Invitrogen, USA) at $37^{\circ} \mathrm{C}$ under $5 \% \mathrm{CO}_{2}$ for $30 \mathrm{~min}$ and washed four times in PBS. Later, they were mounted on a slide and placed under a coverslip. The oocytes were observed under the fluorescence microscope (TE2000-s, Nikon, Japan). Two main distribution features characterized the porcine oocytes mitochondrial distribution pattern: homogeneous or even distribution (Fig. 2A) and heterogeneous or uneven distribution throughout the ooplasm (Fig. 2B-E).

\section{Parthenote production and culture}

A total of 80 oocytes from each group were transferred to the activation medium containing 1.0 $\mathrm{mM} \mathrm{CaCl} 2,0.1 \mathrm{mM} \mathrm{MgCl} 2,0.3 \mathrm{Mm}$ mannitol, and 0.5 mM HEPES for the parthenogenetic activation (PA). Matured oocytes were activated with two pulses of $120 \mathrm{~V} / \mathrm{mm}$ DC for $60 \mathrm{~ms}$ with the Electro-Cell Manipulator BTX 2001 (BTX Inc, USA). Subsequently, the parthenotes were cultured in $2 \mathrm{mM}$ 6-dymethylaminopurine (6-DAMP) for $6 \mathrm{~h}$, and later transferred into PZM-3 medium and incubated at $39^{\circ} \mathrm{C}$ for $7 \mathrm{~h}$ at $5 \% \mathrm{CO}_{2}$ (Huang et al., 2016). We observed cleavage and blastocyst formation on days 2 and 7, respectively, after oocytes activation.

\section{Detection of gene expression with real-time polymerase chain reaction (RT-PCR)}

RT-PCR was used to detect the expression activity of MAPK and MPF genes. RNA was extracted from a total of 100 oocytes from each group by using TRIzol reagent (Invitrogen) as per the manufacturer's instructions. cDNA synthesis was performed for $30 \mathrm{~min}$ at $55^{\circ} \mathrm{C}$ using Omniscript reverse transcription Kit (Invitrogen) with oligo-dT primer, and PCR was performed by using the Maxime PCR Premix with SYBR Green (TaKaRa Bio Inc., Otsu, Japan). The PCR reaction mixture contained specific primers for cDNA samples. The cDNA was amplified under the following conditions: predenaturation at $95^{\circ} \mathrm{C}$ for $3 \mathrm{~min}$, denaturation at $95^{\circ} \mathrm{C}$ for $15 \mathrm{~s}$, annealing at $56^{\circ} \mathrm{C}$ for $30 \mathrm{~s}$, elongation at $72^{\circ} \mathrm{C}$ for $30 \mathrm{~s}$, and final extension at $72^{\circ} \mathrm{C}$ for $5 \mathrm{~min}$ for 40 cycles using Eppendorf Mastercycler (Eppendorf, Hamburg, Germany). We designed primers with Primer 5.0 software on the basis of the mRNA sequences of Sus scrofa genes published in GenBank, which were synthesized by Shanghai bioengineering co., LTD (Shanghai, China). The primers used in the present study had been verified to be available by RT-PCR. Real-time quantitative PCR data were analyzed by employing the comparative $\mathrm{Ct}\left(2^{-\triangle \Delta \mathrm{Ct}}\right)$ method, and the relative expression level of each gene from each cDNA pool was normalized against the reference gene GAPDH. PCR amplification efficiency of each pair of primers was assessed before quantification, and was found to be in an acceptable range (between 0.9 and 1.1).

The primers and Genebank source accessions for each gene are reported in Table 1.

Peer) reviewing PDF | (2020:01:45291:2:0:NEW 12 Aug 2020) 


\section{Statistics}

163 We performed the log transformation of the percentage values before the analyses. The 164 quantitative data were analyzed by least-squares ANOVA using the General Linear Models 165 (GLM) procedures of the Statistical Analysis System (SAS, version 9.4) (Institute, Cary, NC, 166 USA). We corrected Real-time PCR data by using the GAPDH data as a covariate for different analyses. All data were expressed as mean \pm SEM, and different letters, such as a, b,or c over a bar or a column was considered as statistically significant $(\mathrm{p}<0.05)$. All experiments were repeated thrice.

170

\section{Results}

\section{Effects of melatonin on survival and maturation rate after porcine oocytes} maturation culture in vitro

As shown in Table 2., no significant difference in survival rate was observed among the four groups $(\mathrm{p}>0.05)$, however, the maturation rates in the three experiment groups were all significant higher than the Control, and the maturation rate in $10^{-9} \mathrm{~mol} / \mathrm{L}$ group was significant higher than the $10^{-6}$ and $10^{-12}$ group $(\mathrm{p}<0.05)$. There was no significant difference existed between $10^{-6}$ and $10^{-12}$ group ( $\mathrm{p}>0.05$ ). Fig. 1A, and Fig. 1D represents the survival and matured oocytes, respectively. Fig. 1B, C and Fig. 1E, F show that the survival and mature oocytes were confirmed by fluoresent staining.

181

The effect of melatonin on glutathione content of single oocyte in different groups

Table 3 shows that the GSH content of a single oocyte in three experimental groups was significantly higher than the control group $(p<0.05)$; Although the GSH content in $10^{-9} \mathrm{~mol} / \mathrm{L}$ group was the highest, there was no significant difference among the three experimental groups $(\mathrm{p}>0.05)$.

\section{Mitochondrial maturation distribution of porcine oocytes in different groups}

Fig. 3 shows that the proportions of oocytes with better mitochondrial distribution in the $10^{-12}$, $10^{-9}$ and $10^{-6} \mathrm{~mol} / \mathrm{L}$ group were all significantly higher than that in the $0 \mathrm{~mol} / \mathrm{L}$ group, and the proportion in $10^{-9} \mathrm{~mol} / \mathrm{L}$ group was significantly higher than that in the $10^{-12}$ and $10^{-6} \mathrm{~mol} / \mathrm{L}$ group ( $\mathrm{p}<0.05$ ), whereas $10^{-12} \mathrm{~mol} / \mathrm{L}$ group had a significantly higher proportion of oocytes with better mitochondrial distribution than that in the $10^{-6} \mathrm{~mol} / \mathrm{L}$ group $(\mathrm{p}<0.05)$. Fig.2 represents the status of mitochondrial maturation distribution.

\section{To study the developmental potential of the parthenogenetic embryo in different} groups

200 As illustrated in Fig. 4 the cleavage rate in the $10^{-6} \mathrm{~mol} / \mathrm{L}$ and $10^{-9} \mathrm{~mol} / \mathrm{L}$ groups were 
202 and $10^{-12} \mathrm{~mol} / \mathrm{L}$ group $(\mathrm{p}<0.05)$. However, we did not observe a significant difference in the 203 cleavage and blastocyst rate between the $10^{-6} \mathrm{~mol} / \mathrm{L}$ and $10^{-9} \mathrm{~mol} / \mathrm{L}$ groups and the 0 and $10^{-12}$ $204 \mathrm{~mol} / \mathrm{L}$ group $(\mathrm{p}>0.05)$.

\section{The effects of melatonin on the mRNA expression of MPF and MAPK genes in} 206 oocytes

207 Fig.5 demonstrates that the mRNA expression levels of MPF and MAPK genes in the $10^{-9} \mathrm{~mol} / \mathrm{L}$ 208 group were significantly higher than the other three groups $(\mathrm{p}<0.05)$. The MPF gene expression 209 level of $10^{-6} \mathrm{~mol} / \mathrm{L}$ group was higher than those in the 0 and $10^{-12} \mathrm{~mol} / \mathrm{L}$ group $(\mathrm{p}<0.05)$, 210 however, no significant difference existed between the 0 and $10^{-12} \mathrm{~mol} / \mathrm{L}$ group. There was no 211 significant difference in MAPK gene expression between the $10^{-6}$ and $10^{-12}$ group $(\mathrm{p}>0.05)$, 212 whereas, they were both significantly higher than the $0 \mathrm{~mol} / \mathrm{L}$ group $(\mathrm{p}<0.05)$.

213

\section{Discussion}

215 Previous studies have shown the beneficial effect of melatonin on the in vitro maturation 216 (IVM) of porcine oocytes ( $\mathrm{Li}$ et al. 2015), embryo development (Choi et al. 2008), and the 217 in vitro protection of fertilized embryos (Rodriguez-Osorio et al. 2007). We did not find a 218 significant influence on porcine oocyte survival after oocyte had been maturation cultured with 219 different concentration of melatonin for $42 \mathrm{~h}$ in vitro. We attribute this results to the ideal 220 maturation conditions established in our lab, where the culture environment was suitable to meet the requirements of oocyte's energy, nutrients, and other maturation demands (Huang et al., 2016). As shown in Table 2, the lowest survival rates of the four groups was $88.94 \%$. However, the maturation rate was significantly increased in the $10^{-6}, 10^{-9}$ or $10^{-12} \mathrm{~mol} / \mathrm{L}$ group comparing to the $0 \mathrm{~mol} / \mathrm{L}$ group. Because the process of oocyte maturation involves many molecular events and biochemical reactions, which coordinating nuclear and cytoplasmic maturation (AriasA'lvarez et al., 2017), so our study demonstrated that $10^{-12}-10^{-6} \mathrm{~mol} / \mathrm{L}$ melatonin could further promote oocyte maturation in vitro. Besides, we found that different melatonin concentrations can elevate the porcine oocyte maturation quality, as indicated by the single oocyte's GSH content and the higher ratio of the oocyte with better mitochondrial distribution, especially, $10^{-9}$ $\mathrm{mol} / \mathrm{L}$ melatonin was found to be the most effective concentration in the present experiments. Previous studies suggest that melatonin acts as an antioxidant and protects the oocytes from the adverse effect of ROS during in vitro maturation. Thus, it promotes oocyte's maturation and developmental ability (Shi et al., 2009). Melatonin significantly improves the oocytes cytoplasmic maturation by improving the ratio of oocytes with the normal distribution of organelles and by increasing the intracellular GSH and ATP levels (Zhao et al., 2017), which were consistent with our study that melatonin could significantly improve the mitochondrial maturation distribution in cytoplasm. In the recent study by our group, we found that melatonin concentration of $10^{-5} \mathrm{M}$ significantly improved the quality of mitochondria maturation in porcine oocyte as compared to the control group. However, these beneficial effects of melatonin could be blocked by $10^{-5} \mathrm{M}$ luzindole, which is a melatonin receptor antagonist (Yang et al., 2020). As per 
242 oocyte maturation, and $10^{-9} \mathrm{M}$ melatonin is the optimum concentration for porcine oocyte 243 maturation in vitro (Shi et al., 2009). The outcomes of our analysis were in line with this study.

244 The physiological dose of ROS plays an important role in cell growth and metabolism (Rajani et 245 al., 2012) and the enhanced of ROS content in cells can induce DNA damage and lipid 246 peroxidation, disrupt mitochondrial function (Loven 1988; Lord-Fontaine S and Averill-Bates 247 2002). We speculate that $10^{-9} \mathrm{~mol} / \mathrm{L}$ melatonin keeps the ROS content at an appropriate level and 248 protect the oocytes from oxidative stress damage, thereby maintaining the physiological dose of 249 ROS to support the ooplasmic maturation of the porcine oocytes in vitro. From the perspective of 250 the embryo cleavage and blastocyst rate, they were both significantly higher in $10^{-6} \mathrm{~mol} / \mathrm{L}$ and $25110^{-9} \mathrm{~mol} / \mathrm{L}$ groups against the 0 and $10^{-12} \mathrm{~mol} / \mathrm{L}$ group. These results might be correlated with the 252 better maturation quality of porcine oocytes. We had already shown that $10^{-6} \mathrm{~mol} / \mathrm{L}$ and $10^{-9}$ $253 \mathrm{~mol} / \mathrm{L}$ groups exhibit a higher GSH content in single oocyte and a higher ratio of the oocyte with 254 better cytoplasmic mitochondrial distribution, which were essential for embryo development 255 (Huang et al., 2016). Numerous studies have reported that melatonin, an antioxidant, scavenge 256 ROS (Tamura et al., 2012), and promotes porcine oocyte maturation as well as embryonic 257 development (Choi et al., 2008; El-Raey et al., 2011; Lord et al., 2013; Tamura et al., 2009; Tian 258 et al., 2014). Li et al. also tested the concentration of $10^{-6} \mathrm{~mol} / \mathrm{L}-10^{-9} \mathrm{~mol} / \mathrm{L}$ melatonin to the 259 influence of oocyte maturation and development when oocytes were heat stressed, in which $10^{-9}$ $260 \mathrm{~mol} / \mathrm{L}$ melatonin exhibited the best protective effects from heat stress and boosted porcine 261 oocytes maturation and development ( $\mathrm{Li}$ et al., 2015). These studies are in line with our 262 experimental outcomes.

263 The MPF and MAPK genes play an essential role in the maturation and development of oocytes 264 (López-Cardona et al., 2017). Other studies also illuminated the fact that the MPF gene plays a 265 central role in oocyte maturation and embryonic development by regulating oocytes meiosis and 266 cell cycle; also, it promotes nuclear maturation of porcine oocytes (Dadashpour Davachi et al., 267 2017; Liu et al., 2018; Oqani et al., 2017). In our study, the expression pattern of the MPF gene 268 varied with the changes of oocyte maturation quality and developmental potential, and the 269 supplement of melatonin with $10^{-9} \mathrm{~mol} / \mathrm{L}$ is most beneficial to porcine oocytes maturation and 270 development during maturation in vitro, while the higher concentration with $10^{-6} \mathrm{~mol} / \mathrm{L}$ or the 271 lower concentration with $10^{-12} \mathrm{~mol} / \mathrm{L}$ melatonin supplement both decreased the expression of the 272 MPF gene. Nevertheless, another report showed that the most suitable concentration of 273 melatonin for porcine oocyte maturation and development was $10^{-7} \mathrm{~mol} / \mathrm{L}$ ( $\mathrm{Li}$ et al., 2015). $\mathrm{Li}$ et 274 al. studied the porcine oocytes under heat stress conditions $\left(42^{\circ} \mathrm{C}\right.$ for $20-24 \mathrm{~h}$ during IVM). The 275 findings of this study suggested that $10^{-7} \mathrm{~mol} / \mathrm{L}$ melatonin protected and promoted the oocyte 276 maturation and development under heat stress condition; however, in the normal IVM condition, $27710^{-9} \mathrm{~mol} / \mathrm{L}$ melatonin promoted the maturation and development of the oocytes. Previous studies 278 suggested that a high MAPK gene expression activity is an essential marker of oocyte maturation 279 and a necessary criterion for the oocyte's maturation quality (Li et al., 2017; Sun et al., 2016). 280 Melatonin can activate the MAPK protein and regulate the MPF protein by interacting with 281 intracellular transcription factors or cell inhibitory factor (CIF), which control the meiosis of 
282 oocyte and promote oocyte maturation and embryo development (Mayo et al., 2016; Tiwari et 283 al., 2017). However, in our present study, the MAPK gene expression level was showed 284 significantly higher in $10^{-9} \mathrm{~mol} / \mathrm{L}$ goup than the other groups $(\mathrm{p}<0.05)$, which was also consistent 285 with the results of maturation indexes and MPF gene expression. The outcome of the current 286 study shows that the group with $10^{-9} \mathrm{~mol} / \mathrm{L}$ group melatonin supplement exhibits the highest 287 maturation quality and developmental potential consistent with the heightened MPF and MAPK 288 mRNA expression.

289

290

291

292

293

294

295

296

297

298

299

300

301

302

303

304

305

306

307

308

309

310

311

312

313

314

315

316

317

318

319

320

321

\section{Conclusion}

Based on our previous findings, in the current study, we reported the optimum melatoninsupplement concentration $\left(10^{-9} \mathrm{~mol} / \mathrm{L}\right)$ for porcine oocyte maturation culture at $39^{\circ} \mathrm{C}, 5 \% \mathrm{CO}_{2}$, $95 \%$ humidity for $42 \mathrm{~h}$ in the vitro condition. We found increased single oocyte GSH content, better mitochondrial maturation distribution, maturation rate, MPK, and MAPK gene expression in the $10^{-9} \mathrm{~mol} / \mathrm{L}$ group, which increased the developmental potential of oocytes. The outcome of the current study extended our understanding of melatonin-induced porcine oocyte maturation and embryo development, which has provided a reference point for the biotechnological applications of oocyte maturation and development in vitro.

\section{References}

Agarwal A, and Majzoub A. 2017. Role of Antioxidants in Assisted Reproductive Techniques. The world journal of men's health 35:77-93. doi: 10.5534/wjmh.2017.35.2.77.

Arias-Álvarez M, García-García RM, López-Tello J, Rebollar PG, Gutiérrez-Adán A and Lorenzo PL. 2017. In vivo and in vitro maturation of rabbit oocytes differently affects the gene expression profile, mitochondrial distribition, apoptosis and early embryo development. Reprod Fertil Dev 29: 1667-1679. doi: 10.1071/RD15553.

Babayev E, and Seli E. 2015. Oocyte mitochondrial function and reproduction. Current Opinion in Obstetrics and Gynecology 27:175-181. doi: 10.1097/GCO.0000000000000164.

Baek JI, Seol DW, Lee AR, Lee WS, Yoon SY, and Lee DR. 2017. Maintained MPF Level after Oocyte Vitrification Improves Embryonic Development after IVF, but not after Somatic Cell Nuclear Transfer. Molecules and Cells 40:871-879. doi: 10.14348/molcells.2017.0184.

Chappel S. 2013. The role of mitochondria from mature oocyte to viable blastocyst. Obstetrics and gynecology international 2013:183024-183024. doi: 10.1155/2013/183024.

Choi J, Park SM, Lee E, Kim JH, Jeong YI, Lee JY, Park SW, Kim HS, Hossein MS, Jeong YW, Kim S, Hyun SH, and wang WS. 2008. Anti-apoptotic effect of melatonin on preimplantation development of porcine parthenogenetic embryos. Molecular Reproduction and Development 75:1127-1135. doi: 10.1002/mrd.20861.

Cui MS, Fan YP, Wu Y, Hao ZD, Liu S, Chen XJ, and Zeng SM. 2009. Porcine cumulus cell influences ooplasmic mitochondria-lipid distributions, GSH-ATP contents and calcium release pattern after electro-activation. Theriogenology 71:412-421. doi: 10.1016/j.theriogenology.2008.08.008. 
322

323

324

325

326

327

328

329

330

331

332

333

334

335

336

337

338

339

340

341

342

343

344

345

346

347

348

349

350

351

352

353

354

355

356

357

358

359

360

361

Dadashpour Davachi N, Kohram H, Zare Shahneh A, Zhandi M, Goudarzi A, Fallahi R, Masoudi R, Yousefi AR, and Bartlewski PM. 2017. The effect of conspecific ampulla oviductal epithelial cells during in vitro maturation on oocyte developmental competence and maturation-promoting factor (MPF) activity in sheep. Theriogenology 88:207-214. doi: 10.1016/j.theriogenology.2016.09.034.

El-Raey M, Geshi M, Somfai T, Kaneda M, Hirako M, Abdel-Ghaffar AE, Sosa GA, El-Roos MEAA, and Nagai T. 2011. Evidence of melatonin synthesis in the cumulus oocyte complexes and its role in enhancing oocyte maturation in vitro in cattle. Molecular Reproduction and Development 78:250-262. doi: 10.1002/mrd.21295.

Gao C, Han HB, Tian XZ, Tan DX, Wang L, Zhou GB, Zhu SE, and Liu GS. 2012. Melatonin promotes embryonic development and reduces reactive oxygen species in vitrified mouse 2cell embryos. Journal of pineal research 52:305-311. doi: 10.1111/j.1600079x.2011.00944.x.

He YT, Wang W, Shen W, Sun QY, and Yin S. 2019. Melatonin protects against Fenoxapropethyl exposure-induced meiotic defects in mouse oocytes. Toxicology 425:152241. doi: 10.1016/j.tox.2019.152241.

Hoelker M, Kassens A, Salilew-Wondim D, Sieme H, Wrenzycki C, Tesfaye D, Neuhoff C, Schellander K, and Held-Hoelker E. 2017. Birth of healthy calves after intra-follicular transfer (IFOT) of slaughterhouse derived immature bovine oocytes. Theriogenology 97:4149. doi: 10.1016/j.theriogenology.2017.04.009.

Huang JJ, An JY, Liu YW, Guo L, and Cui MS. 2016. Effects of Melatonin on Porcine oocyte Maturation and Parthenogenetic Emvryo Development in vitro. Chinese Journal of Animal Science 52:23-27. doi: 10.3969/j.issn.0258-7033.2016.05.005.

Lee Y, Lee H, Park B, Elahi F, Lee J, Lee ST, Park CK, Hyun SH, and Lee E. 2016. Alphalinolenic acid treatment during oocyte maturation enhances embryonic development by influencing mitogen-activated protein kinase activity and intraoocyte glutathione content in pigs1. Journal of Animal Science 94:3255-3263. doi: 10.2527/jas.2016-0384.

Li Y, Wang Y, Wu Y, Wang B, Chen X, Xu X, Chen H, Li W, and Xu X. 2017. Echinacea pupurea extracts promote murine dendritic cell maturation by activation of JNK, p38 MAPK and NF-кB pathways. Developmental \& Comparative Immunology 73:21-26. doi: 10.1016/j.dci.2017.03.002.

Li Y, Zhang Z, He C, Zhu K, Xu Z, Ma T, Tao J, and Liu G. 2015. Melatonin protects porcine oocyte in vitro maturation from heat stress. Journal of pineal research 59:365-375. doi: 10.1111/jpi.12268.

Liang S, Guo J, Choi JW, Kim NH, and Cui XS. 2017. Effect and possible mechanisms of melatonin treatment on the quality and developmental potential of aged bovine oocytes. Reproduction, Fertility and Development 29:1821. doi: 10.1071/rd16223.

Liu J, Lu X, Wang W, Zhu J, Li Y, Luo L, and Zhang W. 2018. Activity of MPF and expression of its related genes in mouse MI oocytes exposed to cadmium. Food and Chemical Toxicology 112:332-341. doi: 10.1016/j.fct.2017.12.046. 
362

363

364

365

366

367

368

369

370

371

372

373

374

375

376

377

378

379

380

381

382

383

384

385

386

387

388

389

390

391

392

393

394

395

396

397

398

399

400

Lonergan P, and Fair T. 2016. Maturation of Oocytes in Vitro. Annual Review of Animal Biosciences 4:255-268. doi: 10.1146/annurev-animal-022114-110822.

López-Cardona AP, Pérez-Cerezales S, Fernández-González R, Laguna-Barraza R, Pericuesta E, Agirregoitia N, Gutiérrez-Adán A, and Agirregoitia E. 2017. CB1 cannabinoid receptor drives oocyte maturation and embryo development via PI3K/Akt and MAPK pathways. The FASEB Journal 31:3372-3382. doi: 10.1096/fj.201601382rr.

Lord T, Nixon B, Jones KT, and Aitken RJ. 2013. Melatonin Prevents Postovulatory Oocyte Aging in the Mouse and Extends the Window for Optimal Fertilization In Vitro1. Biology of Reproduction 88doi: 10.1095/biolreprod.112.106450.

Lord-Fontaine S and Averill-Bates DA. 2002. Heat shock inactivates cellular antioxidant defenses against hydrogen peroxide: protection by glucose. Free Radic Biol Med. 32, 752765. doi:10.1016/s0891-5849(02)00769-4.

Loven DP. 1988. A role for reduced oxygen species in heat induced cell killing and the induction of thermotolerance. Med Hypotheses 26, 39-50. doi:10.1016/0306-9877(88)90111-9.

Mayo JC, Hevia D, Quiros-Gonzalez I, Rodriguez-Garcia A, Gonzalez-Menendez P, Cepas V, Gonzalez-Pola I, and Sainz RM. 2016. IGFBP3 and MAPK/ERK signaling mediates melatonin-induced antitumor activity in prostate cancer. Journal of pineal research 62:e12373. doi: 10.1111/jpi.12373.

Nikmard F, Hosseini E, Bakhtiyari M, Ashrafi M, Amidi F, and Aflatoonian R. 2016. Effects of melatonin on oocyte maturation in PCOS mouse model. Animal Science Journal 88:586592. doi: 10.1111/asj.12675.

Oqani RK, Lin T, Lee JE, Kim SY, Kang JW, and Jin DI. 2017. Effects of CDK inhibitors on the maturation, transcription, and MPF activity of porcine oocytes. Reproductive Biology 17:320-326. doi: 10.1016/j.repbio.2017.09.003.

Rajani S, Chattopadhyay R, Goswami SK, Ghosh S, Sharma S, and Chakravarty B. 2012. Assessment of oocyte quality in polycystic ovarian syndrome and endometriosis by spindle imaging and reactive oxygen species levels in follicular fluid and its relationship with IVFET outcome. Journal of Human Reproductive Sciences 5:187-193. doi: 10.4103/09741208.101020.

Shi JM, Tian XZ, Zhou GB, Wang L, Gao C, Zhu S-E, Zeng S-M, Tian J-H, and Liu GS. 2009. Melatonin exists in porcine follicular fluid and improves in vitro maturation and parthenogenetic development of porcine oocytes. Journal of pineal research 47:318-323. doi: 10.1111/j.1600-079x.2009.00717.x.

Sun MJ, Zhu S, Li YW, Lin J, Gong S, Jiao GZ, Chen F, and Tan JH. 2016. An essential role for the intra-oocyte MAPK activity in the NSN-to-SN transition of germinal vesicle chromatin configuration in porcine oocytes. Scientific reports 6:23555-23555. doi: 10.1038/srep23555.

Tamura H, Nakamura Y, Korkmaz A, Manchester LC, Tan DX, Sugino N, and Reiter RJ. 2009. Melatonin and the ovary: physiological and pathophysiological implications. Fertility and Sterility 92:328-343. doi: 10.1016/j.fertnstert.2008.05.016. 
401

402

403

404

405

406

407

408

409

410

411

412

413

414

415

416

417

418

419

420

421

422

423

424

425

426

427

428

429

430

431

432

433

434

Tamura H, Takasaki A, Miwa I, Taniguchi K, Maekawa R, Asada H, Taketani T, Matsuoka A, Yamagata Y, Shimamura K, Morioka H, Ishikawa H, Reiter RJ, and Sugino N. 2008. Oxidative stress impairs oocyte quality and melatonin protects oocytes from free radical damage and improves fertilization rate. Journal of pineal research 44:280-287. doi: 10.1111/j.1600-079x.2007.00524.x.

Tamura H, Takasaki A, Taketani T, Tanabe M, Kizuka F, Lee L, Tamura I, Maekawa R, Aasada H, Yamagata Y, and Sugino N. 2012. The role of melatonin as an antioxidant in the follicle. Journal of Ovarian Research 5:5-5. doi: 10.1186/1757-2215-5-5.

Tian X, Wang F, He C, Zhang L, Tan D, Reiter RJ, Xu J, Ji P, and Liu G. 2014. Beneficial effects of melatonin on bovine oocytes maturation: a mechanistic approach. Journal of pineal research 57:239-247. doi: 10.1111/jpi.12163.

Tiwari M, Gupta A, Sharma A, Prasad S, Pandey AN, Yadav PK, Pandey AK, Shrivastav TG, and Chaube SK. 2017. Role of Mitogen Activated Protein Kinase and Maturation Promoting Factor During the Achievement of Meiotic Competency in Mammalian Oocytes. Journal of Cellular Biochemistry 119:123-129. doi: 10.1002/jcb.26184.

Tripathi A, Kumar KVP, and Chaube SK. 2010. Meiotic cell cycle arrest in mammalian oocytes. Journal of Cellular Physiology:n/a-n/a. doi: 10.1002/jcp.22108.

Waiz SA, Raies-ul-Haq M, Dhanda S, Kumar A, Goud TS, Chauhan MS, and Upadhyay RC. 2016. Heat stress and antioxidant enzyme activity in bubaline (Bubalus bubalis) oocytes during in vitro maturation. International Journal of Biometeorology 60:1357-1366. doi: 10.1007/s00484-015-1129-0.

Xiao L, Hu J, Song L, Zhang Y, Dong W, Jiang Y, Zhang Q, Yuan L, and Zhao X. 2019. Profile of melatonin and its receptors and synthesizing enzymes in cumulus-oocyte complexes of the developing sheep antral follicle-a potential estradiol-mediated mechanism. Reproductive biology and endocrinology : RB\&E 17:1-1. doi: 10.1186/s12958-018-0446-7.

Yang L, Wang QK, Cui MS, Li QJ, Mu SQ and Zhao ZM. 2020. Effectof Melatonin on the In Vitro Maturation of Porcine Oocytes, Development of Parthenogenetically Activated Embryos, and Expression of Genes Related to the Oocyte Developmental Capability. Animal: 27,10(2):1-13. doi: 10.3390/ani10020209

Zhao XM, Wang N, Hao HS, Li CY, Zhao YH, Yan CL, Wang HY, Du WH, Wang D, Liu Y, Pang YW, and Zhu HB. 2017. Melatonin improves the fertilization capacity and developmental ability of bovine oocytes by regulating cytoplasmic maturation events. Journal of pineal research 64:e12445. doi: 10.1111/jpi.12445.

Peer) reviewing PDF | (2020:01:45291:2:0:NEW 12 Aug 2020) 


\section{Table $\mathbf{1}$ (on next page)}

The primers and Genebank source accessions for each gene used in the study

RT-PCR primers and Genebank source 
1

Table 1. The primers and Genebank source accessions for each gene used in the study

Table 1. RT-PCR primers and Genebank source.

\begin{tabular}{ccc}
\hline Gene & Primer sequence (5'-3') & Accession number \\
\hline \multirow{3}{*}{ GAPDH } & F:TCAAATGGGGTGATGCTGGT & \\
& & XM_021091114 \\
& R:GCAGAAGGGGCAGAGATGAT & \\
MAPK & F:AGTGCCTACCATGCTTCTCG & XM_021071922 \\
& R:TTGTGGTTGTCCTCAACGGG & \\
MPF & F:ACTGGCTAGTGCAGGTTCAG & XM_003124695 \\
& R:TTGGAGCATCTTCTTGGGCA & \\
\hline
\end{tabular}

5

6

7

8 


\section{Table 2 (on next page)}

The effect of melatonin on the qualities of porcine oocytes maturation in vitro

Within a column, percentages with a common superscript mean no significant difference $(p>0.05)$, and with different superscript $(a-c)$ means a significant difference $(p<0.05)$. Each experiment was repeated thrice. 
1

2 Table 2. The effect of melatonin on the qualities of porcine oocytes maturation in vitro.

3

4

\begin{tabular}{cccc}
\hline $\begin{array}{c}\text { MT concentration } \\
(\mathrm{mol} / \mathrm{L})\end{array}$ & $\begin{array}{c}\text { Total } \\
\text { oocytes }\end{array}$ & $\begin{array}{c}\text { Rate of survival } \\
\text { oocytes }(\%)\end{array}$ & $\begin{array}{c}\text { Rate of matured } \\
\text { oocytes }(\%)\end{array}$ \\
\hline 0 & 200 & $89.67 \pm 1.86^{\mathrm{a}}$ & $78.00 \pm 0.58^{\mathrm{a}}$ \\
$10^{-12}$ & 200 & $89.33 \pm 1.48^{\mathrm{a}}$ & $80.50 \pm 0.76^{\mathrm{b}}$ \\
$10^{-9}$ & 200 & $91.33 \pm 1.97^{\mathrm{a}}$ & $85.50 \pm 1.26^{\mathrm{c}}$ \\
$10^{-6}$ & 200 & $91.67 \pm 1.17^{\mathrm{a}}$ & $81.33 \pm 1.17^{\mathrm{b}}$ \\
\hline
\end{tabular}

5 percentages with a common superscript mean no significant difference ( $p>0.05)$. Each experiment was 6 repeated thrice.

7

8

9

10 


\section{Table 3(on next page)}

The GSH content in a single oocyte of different groups

Within a column, the percentage with different superscript (a-b) means a significant difference $(p<0.05)$. Each experiment was repeated thrice. 
1 Table 3. The GSH content in a single oocyte of different groups

z Within a

4 the

\begin{tabular}{ccc}
\hline MT concentration $(\mathrm{mol} / \mathrm{L})$ & Oocyte numbers & GSH content $(\mathrm{pmol} /$ oocyte $)$ \\
\hline 0 & 100 & $8.25 \pm 0.13^{\mathrm{a}}$ \\
$10^{-12}$ & 100 & $9.25 \pm 0.08^{\mathrm{b}}$ \\
$10^{-9}$ & 100 & $9.34 \pm 0.05^{\mathrm{b}}$ \\
$10^{-6}$ & 100 & $8.99 \pm 0.07^{\mathrm{b}}$ \\
\hline
\end{tabular}

column,

5 percentage with different superscript $(a-b)$ means a significant difference $(p<0.05)$. Each experiment was 6 repeated thrice.

7

8 


\section{Figure 1}

Survival and matured oocytes observed under stereomicroscopy and confirmed by fluorescence staining

A: Stereomicroscopic examination of oocytes. B: survival oocyte FDA staining validated. C:

Dead oocytes showed no or very low fluorescence as red arrow pointed. D: The stereoscopic examination of the matured oocytes with the first polar body expulsed. E: The matured oocytes stained with fluorescent dye Hoechst 33342 showed the two fluorescence. F: Oocytes with no polar body expulsed confirmed by fluorescent dye Hoechst 33342 only showed one fluorescence. 
Fig.1.
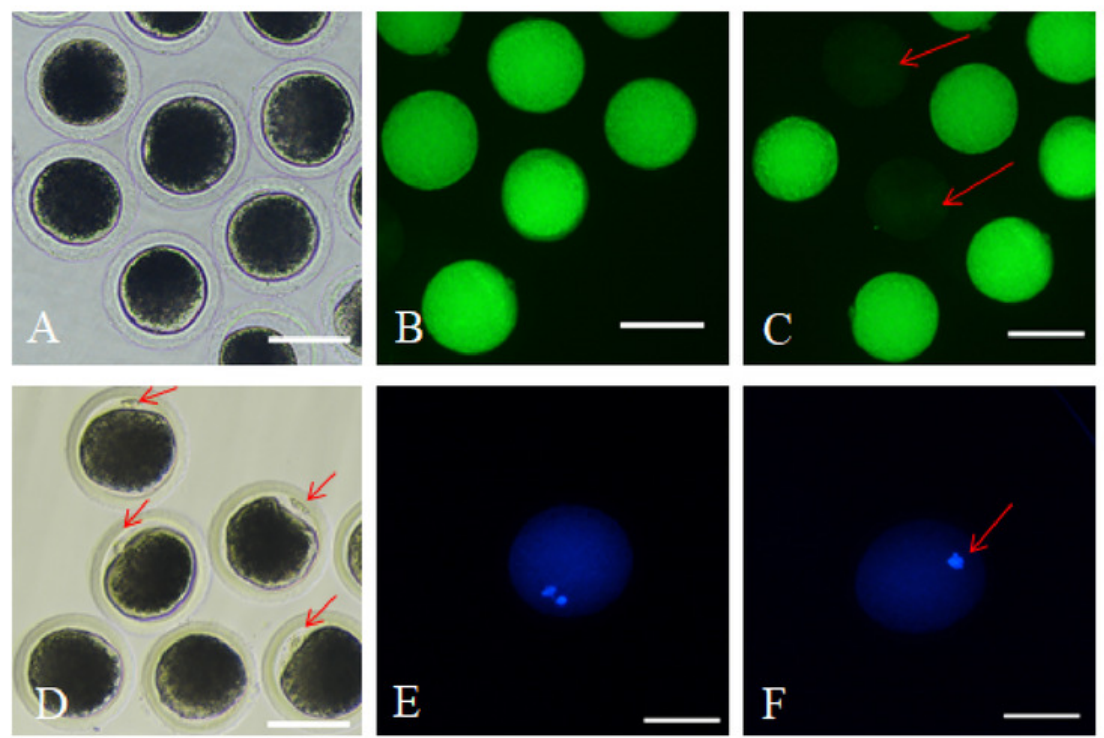
Figure 2

Mitochondrial distribution status in matured oocyte

A: Oocyte with better maturation quality and even distribution of mitochondria in the ooplasm. B-E: Oocytes with heterogeneous and uneven distribution of mitochondria in the ooplasm. 

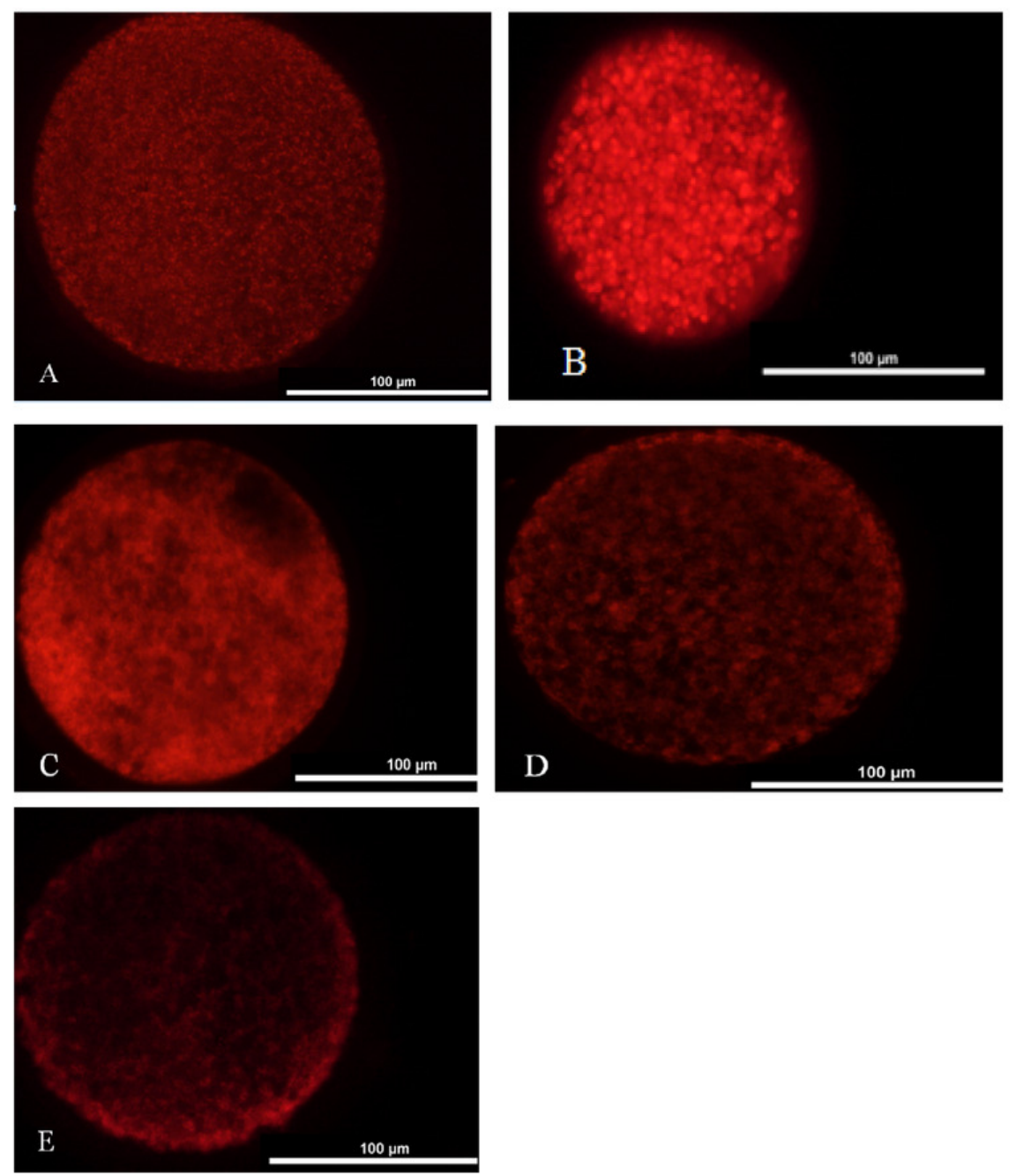


\section{Figure 3}

the proportion of oocyte with better mitochondrial distribution in different groups

The proportion of oocyte with better mitochondria distribution. Different letters (a-d) over a bar mean significant difference $(p<0.05)$. Each experiment was repeated three times. 
Fig. 3

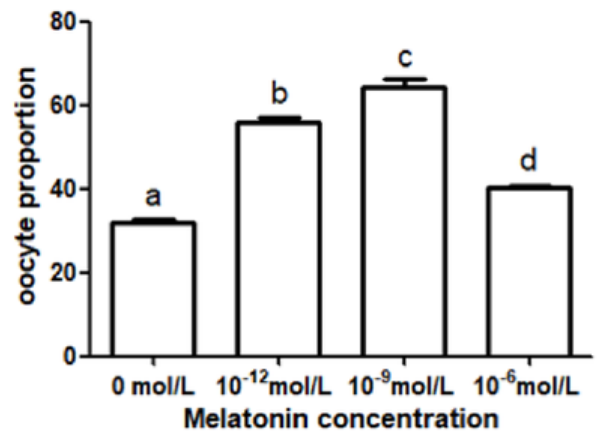


Figure 4

Cleavaged embryos and blastocyst rate in different groups

Developmental potential of the embryos in different groups. Different letters (a-b) over a bar of cleavage rate or over a bar of blastocyst rate represent a significant difference $(p<0.05)$. Each experiment was repeated thrice. 
Fig. 4.

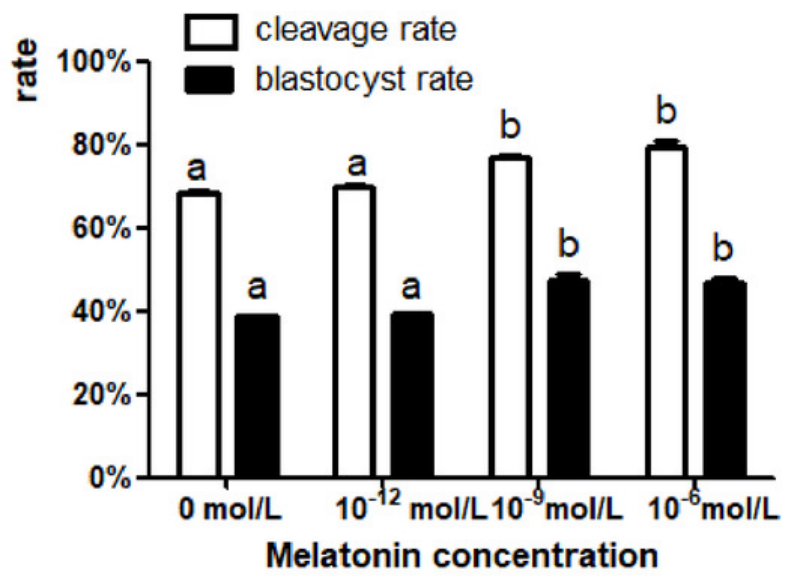




\section{Figure 5}

The mRNA expression of MPF and MAPK genes in ooyctes of differnt groups

MPF and MAPK mRNA expression in different groups. Different letters (a-c) over a bar of MPF expression or different letters $(A-C)$ over a bar of MAPK expression represent a significant difference $(p<0.05)$. Each experiment was repeated thrice. 
Fig. 5

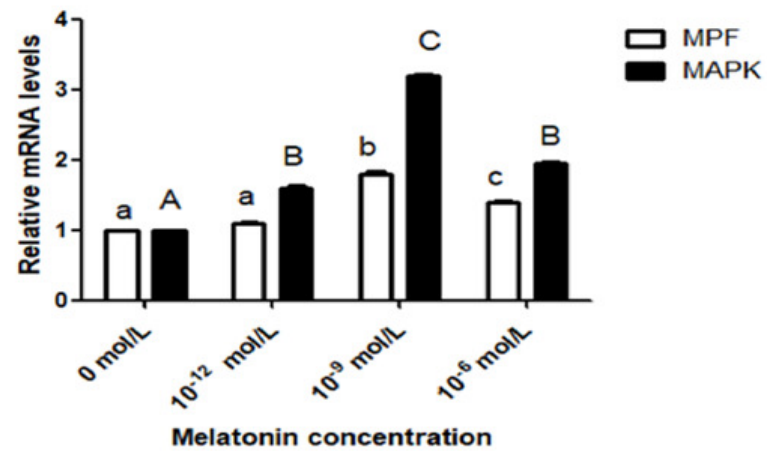

